\title{
Carta do Dr. Jorge Segura aos Colegas Brasileiros
}

Estimados colegas brasileiros,

Será uma honra compartilhar a coordenaçao com o Prof Alberto Sarquis do Curso de Ecodoppler dentro do SIF 2013 - Simposio Internacional de Flebología da SBACV-MG, cujo Presidente é o Prof Francisco Reis Bastos.

O ecodoppler, depois de vinte anos, torna-se cada dia mais importante na prática da medicina moderna facilitando e orientando as nossas atividades médicas.

Este evento científico está seguro, criará laços muito importantes entre nós.

Espero, pessoalmente, poder transmitir minha experiência em ecodoppler vascular aplicada especialmente em Flebología.

Desde já espero contar com a participação de todos voces, o que seguramente nos enriquecerá. Estarei, todo o tempo, à disposição de voces durante minha estadia em Belo Horizonte, MG.

Até breve,

\section{Jorge Segura}

Buenos Aires - Argentina. jorgeasegura@yahoo.com.ar

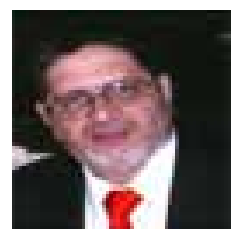

